\title{
Effect of gender difference on platelet reactivity
}

\author{
N. J. Breet • M. A. Sluman • M. A. J. P. J. van Berkel • J. W. van Werkum • \\ H. J. Bouman • A. M. Harmsze • J. C. Kelder • F. Zijlstra • C. M. Hackeng • \\ J. M. ten Berg
}

Published online: 7 September 2011

(C) The Author(s) 2011. This article is published with open access at Springerlink.com

\begin{abstract}
Background Previous studies have suggested that women do not accrue equal therapeutic benefit from antiplatelet medication as compared with men. The physiological mechanism and clinical implications behind this gender disparity have yet to be established.

Methods On-treatment platelet reactivity was determined in 717 men and 234 women on dual antiplatelet therapy, undergoing elective coronary stent implantation. Platelet function testing was performed using arachidonic acid and adenosine diphosphate-induced light transmittance aggregometry (LTA) and the VerifyNow P2Y12 and Aspirin assays. Also the incidence of all-cause death, non-fatal
\end{abstract}

N. J. Breet • M. A. J. P. J. van Berkel · J. W. van Werkum •

H. J. Bouman - J. C. Kelder • C. M. Hackeng - J. M. ten Berg

St Antonius Center for Platelet Function Research,

St Antonius Hospital,

Nieuwegein, the Netherlands

N. J. Breet $\cdot$ M. A. Sluman - J. W. van Werkum $\cdot$ H. J. Bouman •

J. C. Kelder $\cdot$ J. M. ten Berg $(\bowtie)$

Department of Cardiology, St Antonius Hospital,

Koekoekslaan 1,

3435 CM Nieuwegein, the Netherlands

e-mail: j.ten.berg@antoniusziekenhuis.nl

A. M. Harmsze $\cdot$ C. M. Hackeng

Department of Clinical Pharmacy, St Antonius Hospital,

Nieuwegein, the Netherlands

F. Zijlstra

Department of Cardiology, Erasmus Medical Center,

Rotterdam, the Netherlands

C. M. Hackeng

Department of Clinical Chemistry, St Antonius Hospital,

Nieuwegein, the Netherlands acute myocardial infarction, stent thrombosis and ischaemic stroke was evaluated.

Results Women had higher baseline platelet counts than men. Women exhibited a higher magnitude of on-aspirin platelet reactivity using LTA, but not using the VerifyNow Aspirin assay. The magnitude of on-clopidogrel platelet reactivity was significantly higher in women as compared with men with both tests used. The cut-off value to identify patients at risk as well as the incidence of clinical endpoints was similar between women and men (16/234[6.8\%] vs. 62/717[8.6\%], $p=0.38$ ).

Conclusion Although the magnitude of platelet reactivity was higher in women, the absolute difference between genders was small and both the cut-off value to identify patients at risk and the incidence of the composite endpoint were similar between genders. Thus, it is unlikely that the difference in platelet reactivity accounts for a worse prognosis in women.

Keywords Gender Platelet function testing - Clopidogrel · Aspirin · Antiplatelet therapy

\section{Introduction}

Coronary artery disease is the main cause of mortality and morbidity worldwide $[1,2]$. Throughout the last decade improvements in the diagnosis and treatment of atherosclerosis have caused a marked reduction in the morbidity and mortality in men, whereas the rate of recurrent atherothrombotic events, including cardiovascular death, in women has increased $[3,4]$. Since platelet reactivity plays a pivotal role in thrombus formation and atherosclerosis, dual antiplatelet therapy with both aspirin and clopidogrel has become the cornerstone in the treatment of patients 
undergoing coronary stent implantation and those presenting with acute coronary syndrome (ACS) [5, 6]. However, previous studies have suggested that women do not accrue equal therapeutic benefit of antithrombotic therapy $[7,8]$. Although multiple contributing factors have been described, the physiological mechanism behind this gender disparity remains unclear [9]. Therefore, the aim of the present study is to compare the magnitude of ontreatment platelet reactivity between genders in patients on dual antiplatelet therapy undergoing elective coronary stenting.

\section{Methods}

Population and study design

The POPular study (The Do Platelet Function Assays Predict Clinical Outcomes in Clopidogrel Pretreated Patients Undergoing Elective PCI study) was a prospective, observational study including consecutive patients with established coronary artery disease scheduled for elective coronary stent implantation. The entry and exclusion criteria were described in the original publication. The POPular study has established that patients exhibiting a high on-treatment platelet reactivity status were at higher risk for adverse events post-PCI [10].

In the present sub-analysis all patients were on dual antiplatelet therapy with adequate clopidogrel treatment (defined as a maintenance dose of $75 \mathrm{mg}$ daily for $>5$ days, a loading dose of $300 \mathrm{mg}$ at least $24 \mathrm{~h}$ before PCI or $600 \mathrm{mg}$ at least $4 \mathrm{~h}$ prior to $\mathrm{PCI}$ ) and low-dose aspirin of $80-100 \mathrm{mg}$ daily for at least 10 days. Patients were excluded when they had a whole blood platelet count $<150,000 / \mu \mathrm{L}$ or had used medication (other than aspirin or clopidogrel) known to have any effect on platelet reactivity (i.e. NSAIDs, dipyramidole, glycoprotein (GP) IIb/IIIa-inhibitors) within 1 week prior to inclusion. The study was conducted according to the principles of the Declaration of Helsinki and the laws and regulations applicable in the Netherlands. All patients gave written informed consent.

\section{Clinical endpoint}

The clinical endpoint was a combination of all-cause death, non-fatal myocardial infarction (defined as the occurrence of ischaemic symptoms as well as a spontaneous troponin $\mathrm{T}$ value or creatine kinase MB greater than the upper limit of normal), definite stent thrombosis (according to the Academic Research Consortium criteria) [11] and ischaemic stroke. An independent committee, blinded for platelet function data, adjudicated all endpoints through review of source documents of medical records.
Blood sampling

Prior to heparinisation, whole blood was drawn from the femoral or radial artery sheath. Blood samples were collected into Vacuette ${ }^{\circledR}$ tubes (Greiner Bio-one, Frickenhausen, Germany) containing 3.2\% sodium citrate for all platelet function tests. Blood samples for whole blood count were drawn into tubes containing $\mathrm{K}_{3}$-EDTA. Platelet function testing was performed within $2 \mathrm{~h}$ after blood withdrawal.

Platelet function testing

\section{Light transmittance aggregometry}

Light transmittance aggregometry (LTA) was performed using an APACT 4004 aggregometer (LABiTec, Arensburg, Germany) at $37^{\circ} \mathrm{C}$. Platelet poor plasma (PPP) was used as a reference for $100 \%$ aggregation and maximal platelet aggregation (\%) was measured in non-adjusted platelet rich plasma after stimulation with arachidonic acid (AA) in a final concentration of $0.5 \mathrm{mg} / \mathrm{ml}$ to determine on-aspirin platelet reactivity and adenosine diphosphate (ADP) in a final concentration of $20 \mu \mathrm{mol} / \mathrm{L}$ to determine on-clopidogrel platelet reactivity.

\section{VerifyNow ${ }^{\circledR}$ system}

The VerifyNow ${ }^{\circledR}$ (Accumetrics, San Diego, USA) is a whole blood assay designed to measure agonist-induced platelet aggregation. Aspirin-induced platelet reactivity was measured with the aspirin assay, which contains arachidonic acid (AA) (1 mmol/L) and clopidogrel response was measured with the P2Y12 assay. This assay contains $20 \mu \mathrm{mol} / \mathrm{L}$ ADP to induce P2Y12-dependent platelet aggregation, and $22 \mathrm{nmol} / \mathrm{L}$ prostaglandin $\mathrm{E}_{1}\left(\mathrm{PGE}_{1}\right)$ to minimise the contribution of the ADP-activated P2Y1 receptor to platelet aggregation. Results are described as Aspirin Reaction Units (ARU) and P2Y12 Reaction Units (PRU) respectively.

Statistical analysis

Continuous variables were expressed as mean $\pm \mathrm{SD}$, unless otherwise specified, and categorical variables as frequencies (\%). All distributions were checked for normality. Differences in continuous variables were compared by independent $t$-test or Mann-Whitney $U$ test, as appropriate. Dichotomous variables were compared by chi-square test or Fisher's exact test.

Covariate adjustment using a propensity score was performed to reduce confounding factors in the comparison of the magnitude of platelet reactivity between genders. The propensity score was defined as the probability of being a man depending on the baseline characteristics of each patient and used to account for imbalances in the 
distribution of these characteristics between genders. Prior to calculation of the propensity score, missing data were imputed using the program $\mathrm{R}$. The propensity score for each patient was determined using the following characteristics as covariates in a logistic regression model: clinical characteristics (i.e. classic cardiovascular risk factors, previous myocardial infarction (MI), previous percutaneous coronary intervention (PCI) or previous coronary artery bypass graft surgery $(\mathrm{CABG})$, renal failure, left ventricular ejection fraction $<45 \%$ ), co-medication (i.e. use of clopidogrel loading dose and concomitant use of statins, $\beta$-blockers, angiotensin converting enzyme inhibitors, coumarin derivates, calcium channel blocker, proton pump inhibitor, upstream GP IIb/IIIa inhibitor-therapy), laboratory parameters (platelet count, mean platelet volume, white blood cell count, red blood cell count, haemoglobin and haematocrit) and procedural risk factors (i.e. total stent length, number of lesions treated, number of stents implanted, bifurcation stenting, graft stenting, left anterior descending coronary artery (LAD), type of stent implanted (bare-metal stent (BMS), drug-eluting stent (DES) or both) and minimal stent diameter). Subsequently, linear regression analysis was performed to compare the magnitude of platelet reactivity between genders, using the propensity scores as a covariate.

To evaluate whether the cut-off value to identify patients at higher risk of atherothrombotic events was similar between genders, a receiver-operator characteristic (ROC) curve analysis was calculated for each test in both genders. The optimal cut-off level was calculated by determining the smallest distance between the ROC curve and the upper left corner of the graph. To determine whether the cut-off for both genders was similar, a heterogeneity index was calculated. All data were analysed with SPSS version 17.0 (SPSS, Chicago, IL) and R (version $2.9 \mathrm{http} / / /$ r-project.org) and a two-sided $p$-value $<0.05$ was considered significant.

\section{Results}

\section{Study population}

A total of 1069 consecutive patients undergoing elective PCI with stent implantation were enrolled, of whom 951 were on aspirin $>10$ days. The latter comprised the present study population. Due to irregularities in platelet assay supply, as well as technical failure in a minority of platelet function tests, not all platelet function assays were performed in every patient. ADP-induced LTA was performed in 936 patients; AA-induced LTA was performed in 925 patients and the VerifyNow P2Y12 Assay in 940 patients. Since use of the VerifyNow ${ }^{\circledR}$ Aspirin cartridge did not start until halfway through the POPular study, this assay was performed in less than half of the population $(n=422)$.
Of the patients, 234 were female $(24.6 \%)$ and 717 were male $(75.4 \%)$. Baseline characteristics are depicted in Table 1. Women were significantly older than men and were more likely to have a familial history of coronary artery disease (CAD). Furthermore, women had a higher platelet count and a lower haemoglobin value.

Gender-specific differences in platelet reactivity

\section{On-aspirin platelet reactivity}

Women exhibited a higher magnitude of on-aspirin platelet reactivity as compared with men when measured with LTA $(22.4 \pm 11.4 \%$ vs. $19.8 \pm 11.1 \%, p=0.002)$. After adjustment for potential confounders, the difference remained significant $(22.6 \pm 0.8 \%$ vs. $20.0 \pm 0.9 \%, p=0.002$ [mean \pm standard error of the mean (SEM)]). In contrast, women had a similar magnitude of on-aspirin platelet reactivity using the VerifyNow $^{\circledR}$ Aspirin Assay (437 \pm 4.6 vs. $434 \pm 5.6, p=0.06$ after adjustment [mean \pm SEM]). (Fig. 1)

\section{On-clopidogrel platelet reactivity}

The magnitude of on-clopidogrel platelet reactivity was significantly higher in women as compared with men when measured with either LTA $(59.6 \pm 13.2 \%$ vs. $56.9 \pm 14.6 \%, p=$ $0.01)$ or the VerifyNow ${ }^{\circledR}$ P2Y12 assay $(236 \pm 73.9$ vs. $198 \pm$ 73.9, $p<0.0001)$. All differences remained significant after adjustment for potential confounders in multivariate analysis (Fig. 2).

\section{Gender-specific differences in clinical outcome}

Table 2 summarises 1-year clinical outcome. The occurrence of the composite endpoint (62/717 [8.6\%] in males vs. 16/234 $[6.8 \%]$ in females, $p=0.58)$, as well as its single components, was similar between men and women (13/717 [1.8\%] men died vs. 3/234 [1.3\%] women).

Gender-specific differences in ROC curve derived cut-off values

Receiver operator characteristic curve (ROC) analysis demonstrated that the cut-off value to identify patients at higher risk of atherothrombotic events was not significantly different between genders (all $p$-values for heterogeneity $>0.10$ ).

\section{Discussion}

Evidence that gender differences play a role in platelet reactivity was first reported over 30 years ago [12] and this observation has been confirmed in more recent studies 
Table 1 Baseline characteristics of study population

\begin{tabular}{|c|c|c|c|c|}
\hline & $\begin{array}{l}\text { Total population } \\
(n=951)\end{array}$ & $\begin{array}{l}\text { Women } \\
(n=234)\end{array}$ & $\begin{array}{l}\text { Men } \\
(n=717)\end{array}$ & $p$-value \\
\hline \multicolumn{5}{|l|}{ Clinical parameters } \\
\hline Age (years) & $64 \pm 10.6$ & $67 \pm 9.9$ & $63 \pm 10.6$ & $<0.001$ \\
\hline BMI $\left(\mathrm{kg} / \mathrm{m}^{2}\right)$ & $27.3 \pm 3.9$ & $27.2 \pm 4.7$ & $27.3 \pm 3.6$ & 0.607 \\
\hline Current smoker & $102(10.7 \%)$ & $24(10.3 \%)$ & $78(10.9 \%)$ & 0.785 \\
\hline Diabetes mellitus & $175(18.4 \%)$ & $53(22.6 \%)$ & $122(17.0 \%)$ & 0.053 \\
\hline Hypertension & $737(77.5 \%)$ & $186(79.5 \%)$ & $551(76.8 \%)$ & 0.401 \\
\hline Hypercholesterolaemia & $769(80.9 \%)$ & $189(80.8 \%)$ & $580(81.0 \%)$ & 0.936 \\
\hline Familial history & $580(61.4 \%)$ & $171(74.0 \%)$ & $409(57.4 \%)$ & $<0.001$ \\
\hline Prior myocardial infarction & $432(45.4 \%)$ & $94(40.2 \%)$ & $338(47.1 \%)$ & 0.063 \\
\hline Impaired ejection fraction & $133(14.0 \%)$ & $35(15.0 \%)$ & $98(13.7 \%)$ & 0.622 \\
\hline Renal failure & $93(9.8 \%)$ & $22(9.4 \%)$ & $71(9.9 \%)$ & 0.809 \\
\hline \multicolumn{5}{|l|}{ Medication } \\
\hline Loading dose clopidogrel & $489 / 951(51.4 \%)$ & $116(51.1 \%)$ & $373(53.5 \%)$ & 0.527 \\
\hline Proton pump inhibitor & $270(29.4 \%)$ & $70(31.1 \%)$ & $200(28.9 \%)$ & 0.528 \\
\hline Coumarin derivates & $24(2.5 \%)$ & $2(0.9 \%)$ & $21(3.0 \%)$ & 0.073 \\
\hline Calcium channel blocker & $365(39.8 \%)$ & $91(40.4 \%)$ & $274(39.6 \%)$ & 0.821 \\
\hline \multicolumn{5}{|l|}{ Laboratory parameters } \\
\hline Platelet count $\left(\times 10^{\wedge} 9 / \mathrm{L}\right)$ & $273 \pm 79$ & $290 \pm 78$ & $268 \pm 78$ & $<0.001$ \\
\hline White blood cell count $\left(\times 10^{\wedge} 9 / \mathrm{L}\right)$ & $7.7 \pm 2.6$ & $7.9 \pm 3.3$ & $7.7 \pm 2.3$ & 0.359 \\
\hline Haemoglobin (mmol/L) & $8.5 \pm 1.0$ & $7.9 \pm 0.8$ & $8.7 \pm 0.9$ & $<0.001$ \\
\hline \multicolumn{5}{|l|}{ Procedural parameters } \\
\hline Mean no. of stents implanted & 1.57 & $1.55 \pm 0.9$ & $1.57 \pm 0.8$ & 0.15 \\
\hline Minimal stent diameter (mm) & $3.1 \pm 0.8$ & $3.1 \pm 1.4$ & $3.1 \pm 0.6$ & 0.67 \\
\hline Total stent length (mm) & $28.3 \pm 17.1$ & $27.4 \pm 17.2$ & $28.6 \pm 17.1$ & 0.33 \\
\hline Left anterior descending artery & $450 / 951(47.3 \%)$ & $118 / 234(50.4 \%)$ & $448 / 713(46.3 \%)$ & 0.27 \\
\hline Bifurcation lesion & $32 / 951(3.4 \%)$ & $9 / 234(3.8 \%)$ & $23 / 717(3.2 \%)$ & 0.64 \\
\hline Drug-eluting stent & $604 / 946(63.8 \%)$ & $156 / 233(67.0 \%)$ & $332 / 717(62.8 \%)$ & 0.26 \\
\hline
\end{tabular}

Definitions

Hypertension: Systolic blood pressure $>140 \mathrm{mmHg}$ or diastolic blood pressure $>90 \mathrm{mmHg}$

Hypercholesterolaemia: A fasting LDL cholesterol $\geq 3.4 \mathrm{mmol} / \mathrm{L}$ or being on statin therapy at the time of inclusion

Diabetes mellitus: According to the World Health Organization criteria

Family history: One or more first-degree relatives have developed CAD before the age of 55 years (men) or 65 years (women)

Renal insufficiency: Serum creatinine $>120 \mu \mathrm{mol} / \mathrm{L}$

[13-16]. Differences in vessel wall biology between men and women, as well as the direct influence of sex hormones (oestrogens, progesterone or androgens) on platelets or their indirect effect on the vasculature, might be underlying conditions from a biological point of view [4, 17].

Since platelet reactivity plays a pivotal role in thrombus formation and atherosclerosis, dual antiplatelet therapy with both aspirin and clopidogrel has become the mainstay in the treatment of patients undergoing coronary stent implantation and those presenting with $\mathrm{ACS}[5,6,18,19]$. However, both drugs result in a wide interindividual range in platelet inhibition [20, 21] and the association between high ontreatment platelet reactivity and the occurrence of adverse events is well established [22-25]. As a consequence, identification of particular subgroups of patients with high on-treatment platelet reactivity has gained much attention [26]. Women have been reported to exhibit a higher magnitude of both on-aspirin and on-clopidogrel platelet reactivity more often $[13,27]$. However, the cause and clinical implications of these findings are uncertain.

The results from the present study support previous findings that women have higher platelet counts [28] and a higher magnitude of on-treatment platelet reactivity than men $[12,13,29]$. Women exhibited a higher magnitude of onaspirin platelet reactivity as compared with men using light transmittance aggregometry, but not using the VerifyNow 

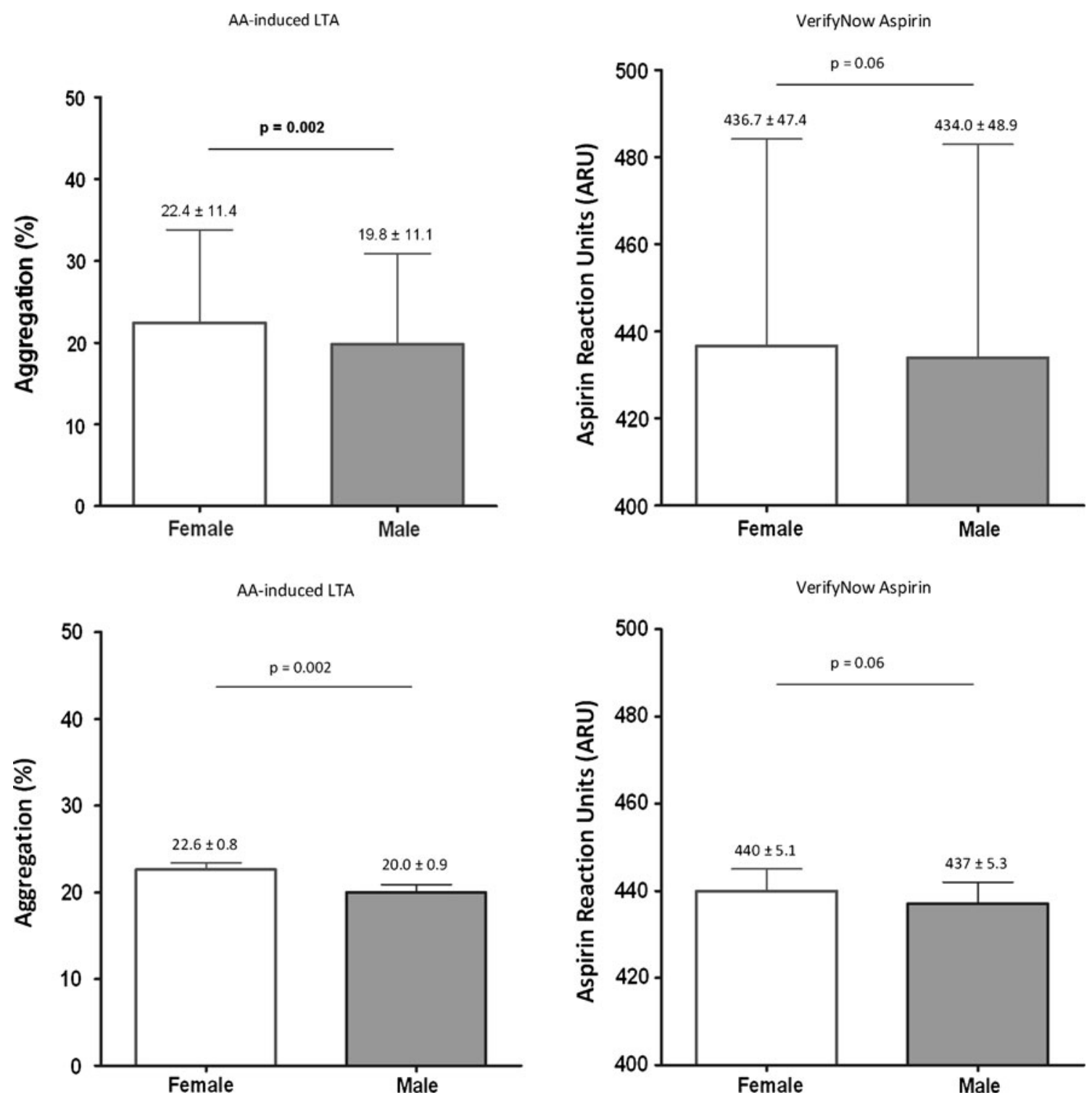

Fig. 1 On-aspirin platelet reactivity. The magnitude of on-aspirin platelet reactivity as assessed by AA-induced LTA and the VerifyNow Aspirin assay prior to (upper part: mean $\pm \mathrm{SD}$ ) and after adjustment for potential confounders (lower part; mean $\pm \mathrm{SEM}$ )

Aspirin assay. This observation is in line with previous studies reporting a poor correlation between platelet function tests $[30,31]$ and might also be due to a decreased statistical power, since the VerifyNow Aspirin sample was performed in only half of the patient population [32]. The magnitude of on-clopidogrel platelet reactivity was significantly higher in women as compared with men regardless of the test used. In addition, the cut-offs to identify patients at higher risk of atherothrombotic events as well as the prevalence of the primary endpoint were similar between genders. Thus, the present study does not support the hypothesis that higher ontreatment platelet reactivity could account for the gender differences in clinical outcome and it remains highly questionable whether this gender-related difference in platelet reactivity has clinical relevance.
Previously reported in vitro data suggest that although women have a higher magnitude of platelet reactivity, the response to aspirin is similar or even larger as compared with men $[13,33]$. This is in line with the observation of a genderspecific meta-analysis on the role of aspirin in primary prevention of cardiovascular disease, demonstrating that aspirin is effective in reducing cardiovascular events in both women and men [7, 34]. To date, there are few data on the effects of clopidogrel in women versus men. Whereas conflicting results have been reported on the association between on-clopidogrel platelet reactivity and gender [9], a recent meta-analysis has established that clopidogrel reduces cardiovascular risk in both men and women [35].

Some issues merit mention. First, the magnitude of platelet reactivity was determined with a single assessment 

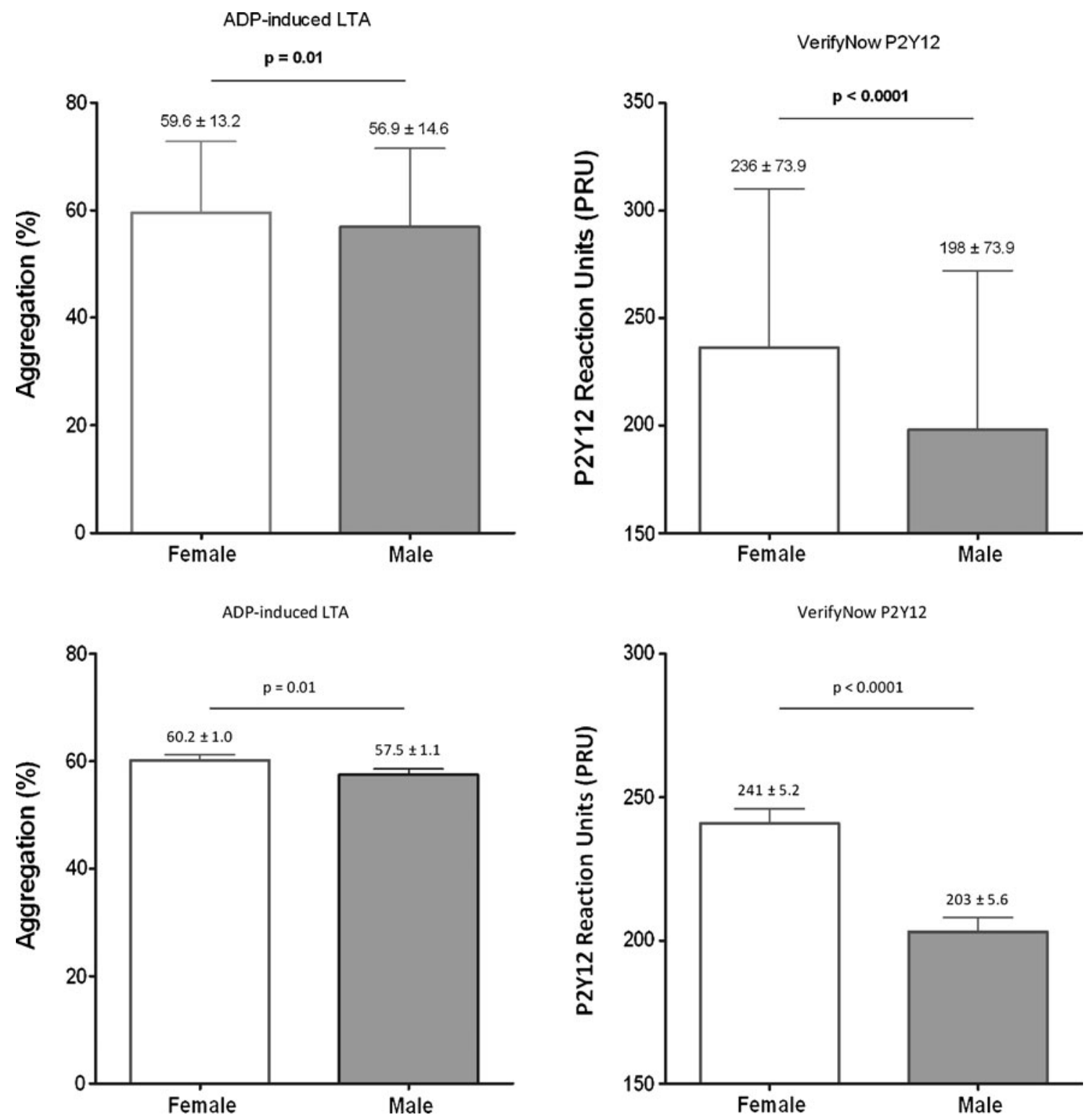

Fig. 2 On-clopidogrel platelet reactivity. The magnitude of on-aspirin platelet reactivity as assessed by ADP-induced LTA and the VerifyNow P2Y12 assay prior to (upper part: mean $\pm \mathrm{SD}$ ) and after adjustment for potential confounders (lower part; mean $\pm \mathrm{SEM}$ )

while patients were already on antiplatelet therapy. In this setting, it is impossible to establish whether the difference in platelet reactivity should be attributed to a higher intrinsic (baseline) platelet reactivity in women or to less response. Second, the role of hormonal influences remains unclear, as menopausal status and menstrual cycle were not assessed in our study, but the numbers of premenopausal women in our study are presumably low.

Higher platelet reactivity at baseline among women has been described previously. Although we support the finding

Table 2 Clinical outcome

\begin{tabular}{lllll}
\hline & Female $(n=234)$ & Male $(n=717)$ & OR (95 CI) & $p$-value \\
\hline Death, MI, ST, stroke & $16(6.8 \%)$ & $62(8.6 \%)$ & $0.78(0.43-1.35)$ & 0.58 \\
Death & $3(1.3 \%)$ & $13(1.8 \%)$ & $0.70(0.13-2.59)$ & 0.47 \\
MI & $11(4.7 \%)$ & $43(6.0 \%)$ & $0.77(0.35-1.53)$ & 0.35 \\
ST & $1(0.4 \%)$ & $8(1.1 \%)$ & $0.38(0.01-2.86)$ & 0.36 \\
Stroke & $4(1.7 \%)$ & $7(0.8 \%)$ & $1.76(0.37-7.01)$ & 0.38 \\
\hline
\end{tabular}


that the magnitude of platelet reactivity is higher in women, the absolute difference between genders is small and both the cut-off value to identify patients at risk and the incidence of the composite endpoint was similar between genders. Thus, it is unlikely that the difference in platelet reactivity accounts for a worse prognosis in women.

Open Access This article is distributed under the terms of the Creative Commons Attribution Noncommercial License which permits any noncommercial use, distribution, and reproduction in any medium, provided the original author(s) and source are credited.

\section{References}

1. Lloyd-Jones D, Adams RJ, Brown TM, et al. Heart disease and stroke statistics - 2010 update: a report from the American Heart Association. Circulation. 2010;121:e46-e215.

2. Lopez AD, Mathers CD, Ezzati M, et al. Global and regional burden of disease and risk factors, 2001: systematic analysis of population health data. Lancet. 2006;367:1747-57.

3. Chandra NC, Ziegelstein RC, Rogers WJ, et al. Observations of the treatment of women in the United States with myocardial infarction: a report from the National Registry of Myocardial Infarction-I. Arch Intern Med. 1998;158:981-8.

4. Capodanno D, Angiolillo DJ. Impact of race and gender on antithrombotic therapy. Thromb Haemost. 2010;104:471-84.

5. Steinhubl SR, Berger PB, Mann III JT, et al. Early and sustained dual oral antiplatelet therapy following percutaneous coronary intervention: a randomized controlled trial. JAMA. 2002;288:2411-20.

6. Mehta SR, Yusuf S, Peters RJ, et al. Effects of pretreatment with clopidogrel and aspirin followed by long-term therapy in patients undergoing percutaneous coronary intervention: the PCI-CURE study. Lancet. 2001;358:527-33.

7. Berger JS, Roncaglioni MC, Avanzini F, et al. Aspirin for the primary prevention of cardiovascular events in women and men: a sex-specific meta-analysis of randomized controlled trials. JAMA. 2006;295:306-13.

8. Boersma E, Harrington RA, Moliterno DJ, et al. Platelet glycoprotein IIb/IIIa inhibitors in acute coronary syndromes: a meta-analysis of all major randomised clinical trials. Lancet. 2002;359:189-98.

9. Jochmann N, Stangl K, Garbe E, et al. Female-specific aspects in the pharmacotherapy of chronic cardiovascular diseases. Eur Heart J. 2005;26:1585-95.

10. Breet NJ, van Werkum JW, Bouman HJ, et al. Comparison between platelet function tests in predicting clinical outcome in patients undergoing coronary stent placement. JAMA. 2010;303:754-62.

11. Cutlip DE, Windecker S, Mehran R, et al. Clinical end points in coronary stent trials: a case for standardized definitions. Circulation. 2007;115:2344-51.

12. Johnson M, Ramey E, Ramwell PW. Sex and age differences in human platelet aggregation. Nature. 1975;253:355-7.

13. Becker DM, Segal J, Vaidya D, et al. Sex differences in platelet reactivity and response to low-dose aspirin therapy. JAMA. 2006;295:1420-7.

14. Gum PA, Kottke-Marchant K, Poggio ED, et al. Profile and prevalence of aspirin resistance in patients with cardiovascular disease. Am J Cardiol. 2001;88:230-5.

15. Blais N, Pharand C, Lordkipanidze M, et al. Response to aspirin in healthy individuals. Cross-comparison of light transmission aggregometry, VerifyNow system, platelet count drop, thromboelastography (TEG) and urinary 11-dehydrothromboxane $\mathrm{B}(2)$. Thromb Haemost. 2009;102:404-11.

16. Yee DL, Sun CW, Bergeron AL, et al. Aggregometry detects platelet hyperreactivity in healthy individuals. Blood. 2005;106:2723-9.

17. Bailey AL, Scantlebury DC, Smyth SS. Thrombosis and antithrombotic therapy in women. Arterioscler Thromb Vasc Biol. 2009;29:284-8.

18. Ruggeri ZM. Platelets in atherothrombosis. Nat Med. 2002;8:122734.

19. Goldschmidt PJ, Lopes N, Crwaford LE, et al. Atherothrombosis and coronary artery disease. Platelets. Elsevier/Academic Press; 2007, p. 629-96

20. Gurbel PA, Bliden KP, Hiatt BL, et al. Clopidogrel for coronary stenting: response variability, drug resistance, and the effect of pretreatment platelet reactivity. Circulation. 2003;107:2908-13.

21. Lau WC, Gurbel PA, Watkins PB, et al. Contribution of hepatic cytochrome P450 3A4 metabolic activity to the phenomenon of clopidogrel resistance. Circulation. 2004;109:166-71.

22. Gurbel PA, Bliden KP, Guyer K, et al. Platelet reactivity in patients and recurrent events post-stenting: results of the PREPARE POSTSTENTING Study. J Am Coll Card. 2005;46:1820-6.

23. Sibbing D, Braun $S$, Morath $T$, et al. Platelet reactivity after clopidogrel treatment assessed with point-of-care analysis and early drug-eluting stent thrombosis. J Am Coll Cardiol. 2009;53:849-56.

24. Marcucci R, Gori AM, Paniccia R, et al. Cardiovascular death and nonfatal myocardial infarction in acute coronary syndrome patients receiving coronary stenting are predicted by residual platelet reactivity to ADP detected by a point-of-care assay: a 12-month follow-up. Circulation. 2009;119:237-42.

25. Bonello L, Tantry US, Marcucci R, et al. Consensus and future directions on the definition of high on-treatment platelet reactivity to adenosine diphosphate. J Am Coll Cardiol. 2010;56:919-33.

26. Angiolillo DJ, Fernandez-Ortiz A, Bernardo E, et al. Platelet function profiles in patients with type 2 diabetes and coronary artery disease on combined aspirin and clopidogrel treatment. Diabetes. $2005 ; 54: 2430-5$.

27. Serebruany VL, Steinhubl SR, Berger PB, et al. Variability in platelet responsiveness to clopidogrel among 544 individuals. J Am Coll Cardiol. 2005;45:246-51.

28. Stevens RF, Alexander MK. A sex difference in the platelet count. Br J Haematol. 1977;37:295-300.

29. Zuern CS, Lindemann S, Gawaz M. Platelet function and response to aspirin: gender-specific features and implications for female thrombotic risk and management. Semin Thromb Hemost. 2009;35:295-306.

30. Lordkipanidze M, Pharand C, Schampaert E, et al. A comparison of six major platelet function tests to determine the prevalence of aspirin resistance in patients with stable coronary artery disease. Eur Heart J. 2007;28:1702-8.

31. Nielsen HL, Kristensen SD, Thygesen SS, et al. Aspirin response evaluated by the VerifyNow Aspirin System and light transmission aggregometry. Thromb Res. 2008;123:267-73.

32. Breet NJ, van Werkum JW, Bouman HJ, et al. High on-aspirin platelet reactivity as measured with aggregation based, COX-1 inhibition sensitive platelet function tests is associated with the occurrence of atherothrombotic events. J Thromb Haemost. 2010;8:2140-8.

33. Harrison MJ, Weisblatt E. A sex difference in the effect of aspirin on "spontaneous" platelet aggregation in whole blood. Thromb Haemost. 1983;50:773-4.

34. Baigent C, Blackwell L, Collins R, et al. Aspirin in the primary and secondary prevention of vascular disease: collaborative meta-analysis of individual participant data from randomised trials. Lancet. 2009;373:1849-60.

35. Berger JS, Bhatt DL, Cannon CP, et al. The relative efficacy and safety of clopidogrel in women and men a sex-specific collaborative meta-analysis. J Am Coll Cardiol. 2009;54:1935-45. 